\title{
Hybrid scheme for modeling LFPs from spiking cortical network models
}

\author{
Espen Hagen ${ }^{1 *}$, Maria L Stavrinou ${ }^{1}$, Henrik Linden ${ }^{2}$, Tom Tetzlaff ${ }^{3}$, Sacha van Albada ${ }^{3}$, David Dahmen ${ }^{3}$, \\ Markus Diesmann ${ }^{3}$, Sonja Gruen ${ }^{3}$, Gaute T Einevoll ${ }^{1}$ \\ From Twenty Second Annual Computational Neuroscience Meeting: CNS*2013 \\ Paris, France. 13-18 July 2013
}

While recordings of extracellular potentials (EP) remain a common method for experimentally measuring neural activity, the interpretation of the low-frequency part, the local field potential (LFP), is not straightforward. Cortical LFPs seem to mainly stem from synaptic inputs, but the net LFP signal from several contributing laminar populations is difficult to assess, as the individual contributions will depend on their locations, the morphologies of the postsynaptic neurons, the spatial distribution of active synapses, and the level of correlations in synaptic inputs [1]. While most comprehensive cortical-network simulations are done with single-compartment models [2], multicompartmental neuronal modeling is in general required to calculate LFPs [1]. Here we present a hybrid
LFP modeling approach where a network of single-compartment LIF neurons generates the spiking activity (Figure 1A), while detailed multicompartment neuronal models are used to calculate the accompanying LFP (Figure 1B-C). Our model describes a $1 \mathrm{~mm}^{2}$ patch of cat $\mathrm{V} 1$, and we incorporate spatially specific pre- to postsynaptic inter- and intra-layer connectivity constrained by experimental observations [3] using reconstructed neuron morphologies of excitatory and inhibitory neurons in layers L2/3-L6 with passive membrane properties. Model specifications of neuron and synapse numbers within populations are taken from [2], while spatial connectivity profiles are based on [3]. Our hybrid simulation framework allows detailed analysis of how the LFP corre-
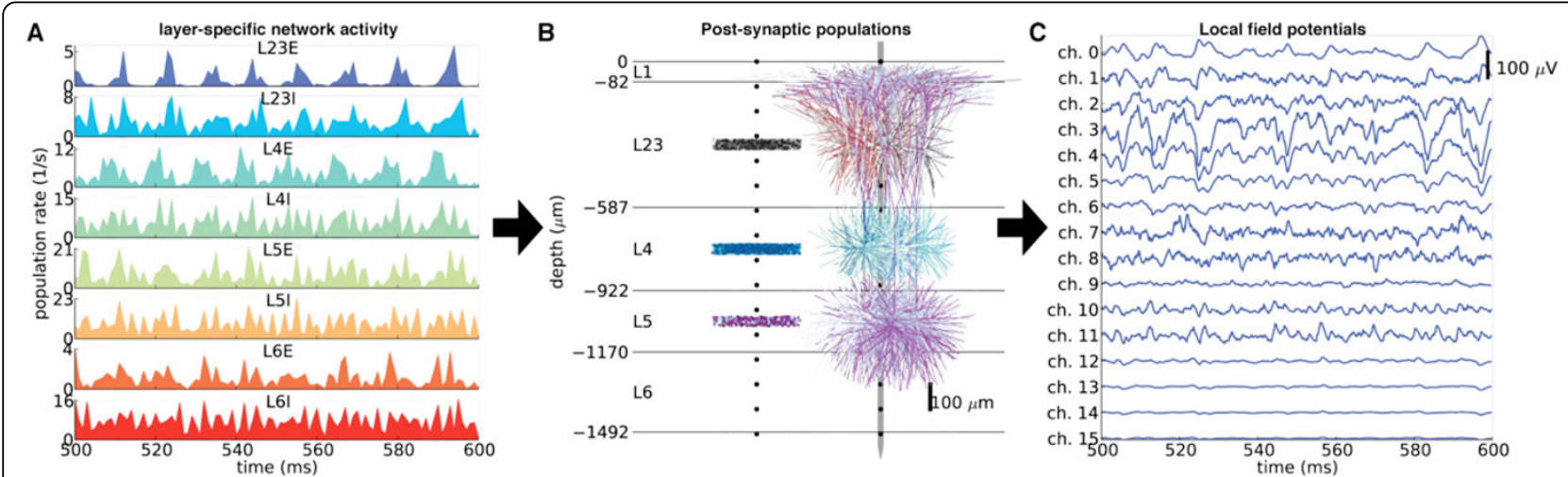

Figure 1 Schematic illustration of the hybrid scheme. (A) Spiking activity generated in network simulations using single-compartment neurons [2] are used as input to multicompartmental neuron models to generate LFPs (B). LFP contributions from each postsynaptic population are calculated and superimposed $(\mathbf{C})$.

\footnotetext{
* Correspondence: espen.hagen@umb.no

'Dept. of Mathematical Sciences and Technology, Norwegian University of Life Sciences, Aas, 1432, Norway

Full list of author information is available at the end of the article
}

\section{Ciomed Central}

(C) 2013 Hagen et al; licensee BioMed Central Ltd. This is an Open Access article distributed under the terms of the Creative Commons Attribution License (http://creativecommons.org/licenses/by/2.0), which permits unrestricted use, distribution, and reproduction in any medium, provided the original work is properly cited. 
lates with network activity and connectivity, and how spatially specific synapse distributions influence the LFP. Spiking network simulations [2] were implemented in NEST (http://www.nest-initiative.org), while simulations of LFPs from morphologically realistic neurons used LFPy (compneuro.umb.no/LFPy) along with NEURON [4].

\section{Acknowledgements}

The research leading to these results has received funding from the European Union Seventh Framework Programme (FP7/2007-2013) under grant agreement no.269921(BrainScaleS) and the Research Council of Norway (eNeuro, Notur)

\section{Author details}

'Dept. of Mathematical Sciences and Technology, Norwegian University of Life Sciences, Aas, 1432, Norway. ${ }^{2}$ Dept. of Computational Biology, Royal Institute of Technology (KTH), Stockholm 10044, Sweden. ${ }^{3}$ Inst. of

Neuroscience and Medicine (INM-6) and Inst. for Advanced Simulation (IAS6), Jülich Research Center and JARA, 52425 Jülich, Germany.

Published: 8 July 2013

\section{References}

1. Linden $\mathrm{H}$, Tetzlaff T, Potjans TC, Pettersen KH, Gruen S, Diesmann M, Einevoll GT: Modeling the spatial reach of the LFP. Neuron 2011, 72:859-872.

2. Potjans TC, Diesmann M: The Cell-Type Specific Cortical Microcircuit: Relating Structure and Activity in a Full-Scale Spiking Network Model. Cereb Cortex 2012, 10.1093/cercor/bhs358.

3. Binzegger T, Douglas RJ, Martin KA: A quantitative map of the circuit of cat primary visual cortex. J Neurosci 2004, 24(39):8441-8453.

4. Hines ML, Davison PA, Muller E: Neuron and Python. Front Neurolnf 2009, 3:1-12.

\section{doi:10.1186/1471-2202-14-S1-P119}

Cite this article as: Hagen et al:: Hybrid scheme for modeling LFPs from spiking cortical network models. BMC Neuroscience 2013 14(Suppl 1):P119.

\section{Submit your next manuscript to BioMed Central} and take full advantage of:

- Convenient online submission

- Thorough peer review

- No space constraints or color figure charges

- Immediate publication on acceptance

- Inclusion in PubMed, CAS, Scopus and Google Scholar

- Research which is freely available for redistribution

Submit your manuscript at www.biomedcentral.com/submit
(Ciomed Central 